\title{
MOTIVASI UNTUK MENINGKATKAN MINAT KULIAH BAGI SISWA SMA BINAAN ASAK SATHORA DI MASA PANDEMI COVID-19
}

\author{
${ }^{1}$ Jurusan Manajemen, Universitas Tarumanagara Jakarta \\ Email: rorlen@fe.untar.ac.id \\ ${ }^{2}$ Jurusan Akuntansi, Universitas Tarumanagara Jakarta \\ Email: miharnit@fe.untar.ac.id \\ ${ }^{3}$ Jurusan Manajemen, Universitas Tarumanagara Jakarta \\ Email: henny@fe.untar.ac.id \\ ${ }^{4}$ Jurusan Akuntansi, Universitas Tarumanagara Jakarta \\ Email: jonnardi@fe.untar.ac.id
}

Rorlen Rorlen $^{1}$, Miharni Tjokrosaputro ${ }^{2}$, Henny Henny ${ }^{3}$ dan Jonnardi Jonnardi ${ }^{4}$

\begin{abstract}
The Covid-19 pandemic caused many of less fortunate students to lose their motivation to continue their education to the university since there are many families being affected by the pandemic. The problems experienced by students and their families are the lack of enthusiasm and motivation to continue to college and the lack of funds. Furthermore, many of these students have to help their parents to earn an income. Therefore, this community engagement is aimed to increase the motivation of those less fortunate high school students from ASAK to continue their study to the university in hope for the better future. The methods that used in this programme was debriefing material extension method and motivation to increase the interest of high school students of ASAK Kembangan in area of West Jakarta. The programme was conducted via Zoom. This community engagement begin with provisioning counselling and motivation, and finished with question and answer. The output of this programme will be an article. According to the students, the result of the measurement using a questionnaire can be very beneficial for them to help self-improvise, develop their mindset and thus will be very eager to participate in the future event that will be held by the Untar team on future opportunities.
\end{abstract}

Keywords: motivation, interest, university

ABSTRAK
Pandemi Covid-19 membuat banyak siswa yang kurang mampu tidak termotivasi untuk melanjutkan sekolahnya ke jenjang perguruan tinggi. Banyak keluarga siswa yang terdampak pandemi Covid-19 ini. Adapun permasalahan yang dialami oleh siswa dan keluarga siswa adalah kurangnya semangat dan motivasi untuk melanjutkan ke perguruan tinggi serta adanya keterbasan biaya. Banyak diantara para siswa tersebut yang harus membantu orang tuanya untuk mencari penghasilan. Oleh karenanya, program pengabdian masyarakat ini bertujuan untuk meningkatkan motivasi para siswa kurang mampu SMA binaan ASAK untuk melanjutkan studinya ke perguruan tinggi agar mereka bisa mendapatkan masa depan yang lebih baik. Target luaran yang akan dicapai adalah artikel publikasi. Metode yang dipakai dalam kegiatan ini adalah metode penyuluhan materi pembekalan dan motivasi untuk meningkatkan minat kuliah bagi anak SMA binaan ASAK Sathora di daerah Kembangan, Jakarta Barat. Pelaksanaan kegiatan dilaksanakan secara telekonferensi melalui Zoom. Kegiatan pengabdian kepada masyarakat ini dimulai dari penyuluhan pembekalan dan motivasi untuk meningkatkan minat kuliah bagi anak SMA binaan ASAK kemudian dilanjutkan dengan tanya jawab. Adapun hasil pengukuran dengan kuesioner atas kegiatan pemberian motivasi ini menurut para siswa dapat sangat mendorong mereka untuk mengembangkan diri, berpola pikir berkembang dan sangat tertarik untuk ambil bagian pada acara yang akan diadakan oleh tim Untar pada kesempatan yang akan datang.

Kata Kunci: motivasi, minat, kuliah

\section{PENDAHULUAN}

\subsection{Analisis Situasi}

Beberapa dekade terakhir, pendidikan tinggi berperan penting untuk mendapatkan pekerjaan yang layak bagi seseorang. Pendidikan seseorang di perguruan tinggi memampukan seseorang untuk berkompetisi dengan menciptakan pengetahuan dan keterampilan yang diperlukan seseorang untuk mendapatkan pekerjaan (Sadeghzadeh et al., 2015). 
Lebih jauh, pendidikan di perguruan tinggi diperlukan untuk mendapatkan pekerjaan yang lebih baik. Bagi anak dari keluarga kurang mampu, kesempatan untuk meraih pendidikan di perguruan tinggi menjadi hal yang sulit diraih. Selain itu, ketidakmampuan menempuh pendidikan di perguruan tinggi dapat menimbulkan ketidaksetaraan dalam mendapatkan kesempatan hidup yang lebih baik. Hal ini diakibatkan oleh karena mahalnya pendidikan di perguruan tinggi. Penelitian dari Gregg et al. (2016) menunjukkan bahwa anak-anak dari keluarga mampu dapat berpenghasilan lebih banyak sepanjang hidup dibandingkan rekan-rekan mereka dari keluarga yang kurang mampu, dengan tingkat ketidaksetaraan kesempatan yang tinggi. Untuk mengatasi kesenjangan tersebut, maka pendidikan di perguruan tinggi diperlukan sebagai salah satu cara untuk meningkatkan daya saing anak-anak kurang mampu tersebut, sehingga mereka bisa mendapatkan kesempatan untuk mendapatkan pekerjaan yang lebih baik dan masa depan yang lebih cerah.

Selain itu, peran potensial pendidikan tinggi adalah untuk meningkatkan mobilitas sosial, mengikis perbedaan sosial-ekonomi dalam akses dan keluaran dari universitas, serta menambah kontribusi baru pada pencapaian universitas untuk mengikis perbedaan berdasarkan latar belakang keluarga, dan bagaimana hasil dari gelar yang dicapai bisa bervariasi berdasarkan pendapatan orang tua (Crawford et al., 2016).

Masalah yang dihadapi oleh mitra PKM adalah motivasi anak-anak SMA binaan ASAK untuk melanjutkan studi ke perguruan tinggi. Menurut Vallerand (1992) salah satu konsep terpenting dalam pendidikan adalah motivasi. Lebih jauh lagi, motivasi adalah konsep yang sangat kompleks yang dipengaruhi oleh sejumlah besar faktor, tetapi secara umum dapat dirangkum menjadi dua, yaitu motivasi ekstrinsik atau intrinsik. Pengaruh motivasi secara ekstrinsik mengacu pada faktorfaktor eksternal dan pengaruh motivasi secara intrinsik mengacu pada faktor-faktor internal yang berkaitan dengan individu. Motivator internal yaitu kebutuhan intrinsik yang memuaskan seseorang, sedangkan motivator eksternal dianggap sebagai faktor lingkungan yang memotivasi seseorang (Bassy, 2002).

Adapun motivasi awal untuk melanjutkan ke perguruan tinggi biasanya berasal dari orang tua dan SMA asal (Schmidt, 2014). Selain itu, pengalaman dari orang lain yang dipercaya memiliki pengalaman tentang universitas dapat mempermudah siswa dalam mempersiapkan diri untuk meneruskan ke jenjang pendidikan yang lebih tinggi (York-Anderson \& Bowman, 1991).

Dari beberapa studi, diperoleh hasil bahwa selain faktor-faktor diatas, terdapat faktor pendorong motivasi siswa untuk melanjutkan ke perguruan tinggi, yaitu beasiswa. Penelitian dari Saenz dan Barrera (2007) menemukan bahwa faktor biaya kuliah sangat menjadi perhatian bagi anak yang kurang mampu, karena mereka sulit mendapatkan beasiswa dan mereka harus bekerja paruh waktu atau bekerja secara penuh untuk mencukupi kebutuhan hidupnya. Meskipun demikian, anak-anak kurang mampu memiliki kesadaran bahwa pendidikan di perguruan tinggi dapat meningkatkan potensi pendapatan mereka di kemudian hari.

Meskipun demikian, banyak diantara para siswa yang kurang mampu tersebut tidak termotivasi untuk melanjutkan sekolahnya ke jenjang perguruan tinggi. Berbagai alasan yang mereka kemukakan, diantaranya adalah keterbatasan waktu dan biaya. Hal ini dikarenakan banyak diantara para siswa tersebut yang harus membantu orang tuanya untuk mencari nafkah.

ASAK adalah kepanjangan dari Ayo Sekolah Ayo Kuliah. Awal mula program Ayo Sekolah lahir dari seorang umat Paroki Bojong Indah, Santo Thomas Rasul (Sathora) yaitu Bapak Justinus Yanto Jayadi Wibisono. Beliau terinspirasi World Vision yang dengan caranya membantu anak-anak 
yang putus sekolah. Pada bulan Juli 2007 lahirlah secara resmi program Ayo Sekolah bekerja sama dengan Seksi Pengembangan Sosial Ekonomi (PSE). Sejumlah 60 anak menerima santunan dari program Ayo Sekolah Sathora saat diluncurkannya program ini yang bertepatan dengan tahun ajaran baru.

Semula dana bantuan PSE bersumber dari 25\% kolekte Misa setiap bulan, kini Pengurus/Tim ASAK harus bekerja berbasis data. Selain merapikan data administratif dan mencari penyantun, tim ASAK melakukan kunjungan ke rumah calon anak santun. Sungguh menggembirakan, meskipun hanya dari mulut ke mulut, dalam waktu seminggu, kebutuhan 60 penyantun dapat terpenuhi.

Gerakan kemanusiaan ini terus berjalan. Di tahun ketiga, cakupan ditingkatkan. Tidak hanya sampai sekolah SMA, tetapi sampai kuliah. Dari Paroki Sathora, Pak Yanto diminta untuk mempresentasikannya di 8 paroki yang ada di Dekenat Jakarta Barat. Mulai dari Santo Thomas Rasul ke Paroki Maria Kusuma Karmel Meruya, dan terus bergulir ke paroki-paroki lain di KAJ. Paroki Fransiskus Asisi Tebet merupakan paroki ke 30 yang menerapkan program ASAK pada tanggal 16 Februari 2014 lalu.

Program gerakan ASAK cepat berkembang karena aksi kemanusiaan ini ditunjang oleh dukungan kuat dari hirarki Gereja. Tanggal 14 Februari 2011, program ini dipresentasikan pada pertemuan para imam se-KAJ dan mendapat dukungan penuh dari Uskup KAJ. Bahkan setiap peluncuran gerakan ASAK di Paroki selalu dihadiri oleh Uskup atau salah satu staf Kuria: Vikjen, Vikep, Sekretaris, Ekonom, dan Ketua/Wakil Komisi PSE KAJ.

Saat ini sudah ada 55 paroki di KAJ yang menjalankan program Ayo Sekolah. Di KAJ, program Ayo Sekolah sudah menyantuni 4.920 anak. Sedangkan program Ayo Kuliah menyantuni 719 anak dan 35 anak di seminari. Maka jumlah total anak santun program Ayo Sekolah Ayo Kuliah (ASAK) adalah 5.674 anak dengan 3.211 orang penyantun, dengan jumlah alumni sebanyak 1.800 orang. Adapun mitra dari pengabdian kepada masyarakat ini adalah anakanak SMA kurang mampu binaan ASAK paroki Santo Thomas Rasul, Kembangan, Jakarta Barat.

\section{Gambar 1}

Foto Kondisi Rumah Penerima Bantuan ASAK

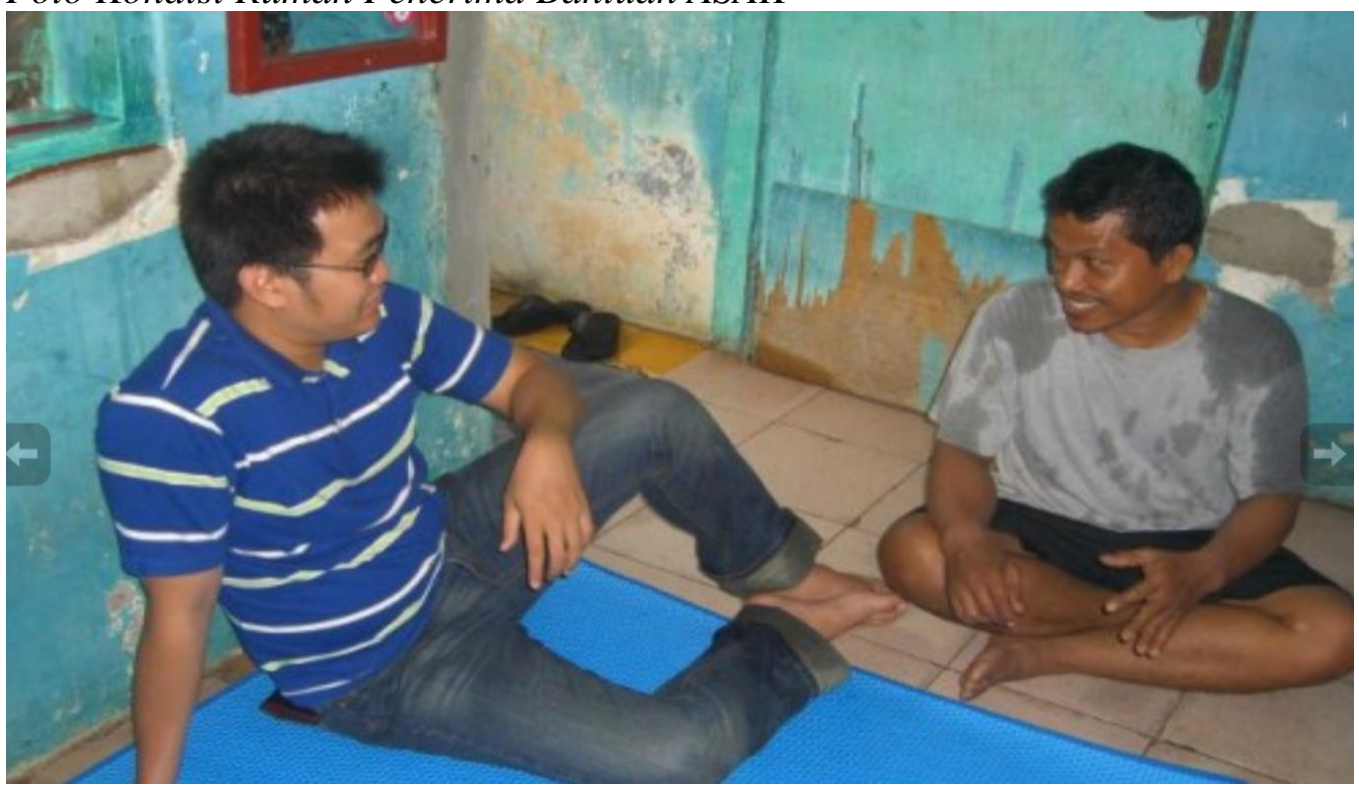


Dibawah ini ditampilkan beberapa foto yang menunjukkan kondisi rumah beberapa penerima bantuan dari ASAK pada saat dilakukan wawancara awal, dimana foto tersebut memperlihatkan bahwa penerima bantuan ASAK betul-betul membutuhkan bantuan untuk kelangsungan studi anak-anak mereka. Kondisi Rumah Penerima Bantuan ASAK dapat dilihat pada Gambar 1.

Berdasarkan latar belakang tersebut diatas, maka pengabdian kepada masyarakat yang diusulkan adalah pemberian pembekalan motivasi untuk meningkatkan minat kuliah bagi siswa SMA binaan ASAK Sathora di daerah Kembangan, Jakbar.

\subsection{Permasalahan Mitra}

Terdapat dua masalah pokok yang menjadi permasalahan dari mitra pengabdian kepada masyarakat, dalam hal ini ASAK Sathora. Masalah yang pertama adalah bagaimana menumbuhkan semangat dan motivasi untuk para siswa SMA binaan ASAK paroki Santo Thomas Rasul untuk melanjutkan ke perguruan tinggi, mengingat mereka memiliki keterbatasan biaya, bahkan sekarang mereka bersekolah pun dengan pembiayaan dari donatur ASAK. Kebanyakan dari anak-anak binaan ASAK merasa bahwa mereka tidak perlu melanjutkan ke perguruan tinggi karena keterbatasan biaya dan mereka lebih baik langsung terjun ke dunia kerja sebagai lulusan. Hal ini menimbulkan kecemasan pada pihak ASAK, karena salah satu tujuan ASAK adalah pengentasan kemiskinan dari sisi penyediaan pendidikan bagi anak kurang mampu.

Berbagai cara telah dilakukan oleh para relawan ASAK untuk menumbuhkan semangat anak-anak binaan ASAK tersebut agar memiliki kemauan untuk melanjutkan ke perguruan tinggi. Pemberian pengarahan untuk menumbuhkan motivasi ini dibutuhkan oleh anak-anak binaan ASAK tersebut, agar mereka tertarik untuk melanjutkan pendidikan ke tingkat yang lebih tinggi, sebagai salah satu upaya untuk dapat keluar dari jeratan kemiskinan akibat kurangnya pendidikan yang layak.

Adapun masalah yang kedua adalah bagaimana seluk beluk kehidupan mahasiswa di perguruan tinggi. Hal ini mengarahkan para siswa SMA tersebut tentang gambaran yang tepat kehidupan di dunia perguruan tinggi. Secara khusus, kami akan memperkenalkan seluk beluk kehidupan mahasiswa di dunia perguruan tinggi khususnya Fakultas Ekonomi dan Bisnis (FEB) secara lebih detail, mengingat fakultas ekonomi dan bisnis adalah fakultas yang memiliki lulusan yang banyak dibutuhkan dunia kerja.

\subsection{Solusi Mitra}

Berdasarkan analisis situasi pada pendahuluan, maka solusi yang ditawarkan pada kegiatan PKM ini adalah pemberian motivasi untuk meningkatkan minat kuliah bagi siswa SMA binaan ASAK Sathora untuk melanjutkan pendidikan ke Perguruan Tinggi.

Pemberian motivasi untuk meningkatkan minat kuliah di bidang ekonomi untuk siswa SMA binaan ASAK di daerah Kembangan, Jakbar akan disampaikan oleh tim PKM FEB secara bergantian yang disertai dengan tanya jawab dengan siswa-siswa yang menjadi peserta. Berbagai topik dikemukakan agar siswa-siswa memperoleh gambaran tentang perguruan tinggi beserta seluk beluk kehidupan di perguruan tinggi. Selain itu, siswa SMA tersebut akan diberi penjelasan tentang berbagai jurusan di universitas sesuai peminatan mereka, terutama tentang fakultas ekonomi dan bisnis.

\section{METODE PELAKSANAAN PKM}

Metode yang dipakai dalam Pengabdian Kepada Masyarakat (PKM) ini adalah metode penyuluhan motivasi untuk meningkatkan minat kuliah bagi siswa SMA binaan ASAK di daerah Kembangan, 
Jakarta Barat. Hal ini digunakan untuk memberikan motivasi untuk tetap mau maju selama masa pandemi Covid-19 bagi siswa SMA tersebut beserta tips kehidupan di perguruan tinggi.

Materi yang akan diberikan dalam Pengabdian Kepada Masyarakat di siswa SMA binaan ASAK Sathora di daerah Kembangan terdiri dari:

1) Motivasi untuk meningkatkan minat kuliah bagi siswa SMA

2) Tips agar dapat lebih sukses di perguruan tinggi

Tahapan metode pelatihan dalam pelaksanaan Pengabdian Kepada Masyarakat tersebut terdiri dari:

1) Penyuluhan motivasi untuk meningkatkan minat kuliah bagi siswa SMA binaan ASAK

2) Tanya jawab

Kegiatan ini akan dilakukan pada tanggal 17 Maret 2021 selama satu hari yang dimulai dengan acara pembukaan, pembagian materi, penjelasan isi materi, sharing dan tanya jawab.

Kegiatan Pengabdian Kepada Masyarakat (PKM) ini didukung penuh oleh perguruan tinggi Universitas Tarumanagara melalui dana yang diberikan kepada tim pengusul PKM. Tim pengusul adalah tim yang telah memperoleh sertifikasi dosen, sehingga setiap semester pasti akan melakukan Tri Dharma Perguruan Tinggi, salah satunya adalah kegiatan Pengabdian Kepada Masyarakat (PKM). Kegiatan PKM yang telah dilakukan tim pengusul selama tujuh tahun terakhir adalah kegiatan yang sesuai dengan spesialisasi bidangnya yaitu Pemasaran, Akuntansi Keuangan, Perpajakan, Manajemen Keuangan, Penganggaran, Matematika Ekonomi, dan Audit.

Pembagian tugas tim dalam persiapan, pelaksanaan dan pelaporan hasil kegiatan Pengabdian Kepada Masyarakat (PKM) dapat dilihat pada Tabel 1.

\section{Tabel 1}

Tugas Tim Pelaksana PKM

\begin{tabular}{|c|c|c|}
\hline No & Tim Pelaksana Pkm & Tugas \\
\hline 1 & Dr. Miharni Tjokrosaputro, SE, MM & $\begin{array}{l}\text { a. Menyusun proposal PKM } \\
\text { b. Membuat persiapan untuk pelaksanaan PKM } \\
\text { c. Melaksanakan kegiatan PKM } \\
\text { d. Menghadiri Monev PKM yang diselenggarakan } \\
\text { oleh LPPM }\end{array}$ \\
\hline 2 & Henny, SE, MSi, Ak, CA, BKP & $\begin{array}{l}\text { a. Menyusun proposal PKM } \\
\text { b. Melaksanakan kegiatan PKM } \\
\text { c. Menghadiri Monev PKM yang diselenggarakan } \\
\text { oleh LPPM } \\
\text { d. Menyusun laporan keuangan PKM } \\
\end{array}$ \\
\hline 3 & Rorlen, SE, MM & $\begin{array}{l}\text { a. Melaksanakan kegiatan PKM } \\
\text { b. Menyusun laporan kemajuan PKM } \\
\text { c. Menyusun laporan akhir PKM }\end{array}$ \\
\hline 4 & Dr. Jonnardi, SE, MM, CA, CPA & $\begin{array}{l}\text { a. Menyusun laporan kemajuan PKM } \\
\text { b. Menyusun laporan akhir PKM } \\
\text { c. Presentasi seminar }\end{array}$ \\
\hline 5 & $\begin{array}{ll}\text { a. } & \text { Gisella Cindy (NIM: } 115180047) \\
\text { b. Irenia Binardi Wijaya (NIM: } \\
\text { 115180055) }\end{array}$ & $\begin{array}{l}\text { c. Membuat artikel hasil kegiatan PKM } \\
\text { d. Membuat poster hasil kegiatan PKM untuk } \\
\text { kegiatan Research Week } 2021\end{array}$ \\
\hline
\end{tabular}

Tahapan kegiatan Pembekalan dan Motivasi Untuk Meningkatkan Minat Kuliah Bagi Anak SMA Kurang Mampu Binaan ASAK di Daerah Kembangan Jakarta Barat ini terbagi menjadi 3 tahap, 
yaitu: (1) tahap persiapan, (2) tahap pelaksanaan, dan (3) tahap pelaporan. Gambaran secara rinci untuk masing-masing tahapan akan diuraikan dalam paparan berikut ini:

\section{1) Tahap Persiapan}

Tahap persiapan dimulai pada bulan Februari 2020, dimana tim penulis mengawali kegiatan persiapan kegiatan PKM dengan penyusunan proposal dan melakukan identifikasi masalah pada mitra. Untuk itu, penulis menghubungi pihak ASAK Santo Thomas Rasul dan melakukan wawancara untuk menemukan kebutuhan mitra.

Berdasarkan wawancara yang telah dilakukan dan setelah proses identifikasi masalah selesai, maka masalah dirumuskan dalam proposal PKM. Setelah itu, proposal kegiatan tersebut disampaikan kepada pihak mitra dengan judul kegiatan "Pembekalan dan Motivasi Untuk Meningkatkan Minat Kuliah Bagi Anak SMA Kurang Mampu Binaan ASAK di Daerah Kembangan Jakarta Barat". Beberapa hari kemudian penulis mendapatkan surat pernyataan kesediaan yang ditandatangani oleh Ketua ASAK Santo Thomas Rasul, yaitu Ibu Agnes Widyanti sebagai mitra PKM.

Penyusunan materi pelatihan yang akan diberikan kepada para peserta pelatihan dibuat sejak bulan Mei 2020. Materi pelatihan yang disusun terdiri dari beberapa topik, antara lain:

a. Perkenalan

b. Motivasi

c. Growth Mindset vs Fixed Mindset

d. Perbedaan SMA dan Kuliah

e. Jurusan-jurusan di Universitas.

f. Penutup.

Dikarenakan pada bulan Mei 2020 sudah terjadi pandemi Covid-19, maka penulis berdiskusi kembali dengan ketua ASAK tentang kemungkinan dilanjutkannya kegiatan PKM ini melalui teleconference dengan aplikasi Zoom. Adapun tim dari ASAK menyetujui hal ini.

Untuk mematangkan rencana kegiatan ini, pada tanggal 2 Juli 2020 telah dilakukan secara teleconference antara tim PKM dan pengurus ASAK seperti yang dapat dilihat pada Gambar 2 .

\section{2) Tahap Pelaksanaan}

Pemberian materi PKM kepada mitra PKM telah dilakukan 1 hari sebelum kegiatan dilangsungkan. Adapun acara berlangsung pada tanggal 17 Maret 2021 pada pukul 17.00 - 18.30 melalui Zoom. Dari 14 peserta yang mendaftar, semuanya hadir. Selain itu, ada 2 orang pengurus ASAK Santo Thomas Rasul yang ikut ambil bagian dalam acara tersebut. Adapun susunan acara pada saat berlangsungnya kegiatan dapat dilihat pada Tabel 2. Acara berjalan lancar, dan anak-anak menanggapi dengan antusias dengan beberapa pertanyaan. Pelaksanaan kegiatan PKM dapat dilihat pada Gambar 3.

\section{3) Tahap Pelaporan}

Kegiatan pembuatan laporan dibuat setelah kegiatan PKM pemberian motivasi berkuliah selesai dilakukan. Sedangkan evaluasi hasil kegiatan ini dapat dilihat dari meningkatnya daya juang anak-anak binaan ASAK, perubahan pada pola pikir serta jumlah anak-anak binaan ASAK yang melanjutkan studi ke jenjang perkuliahan juga meningkat. Dengan 
adanya peningkatan kearah positif inilah diharapkan sebagai indikator keberhasilan pelaksanaan kegiatan PKM kami.

Tabel 2

Susunan Acara Kegiatan Pemberian Motivasi Kuliah Anak ASAK

\begin{tabular}{ll}
\hline \multicolumn{1}{c}{ Waktu } & \multicolumn{1}{c}{ Materi } \\
\hline $17.00-17.10$ & $\begin{array}{c}\text { Pembukaan oleh ibu Lanny (Ketua ASAK) dan Doa oleh ibu Cecilia (Pengurus } \\
\text { ASAK untuk SMA) }\end{array}$ \\
\hline $17.10-17.20$ & - Perkenalan dari tim PKM FEB Untar \\
\hline $17.20-18.00$ & - Penyampaian Materi \\
\hline $18.00-18.20$ & - Sharing dari tim PKM FEB Untar \\
\hline $18.20-18.30$ & - Tanya Jawab
\end{tabular}

\section{Gambar 2}

Foto Pada Saat Rapat Secara Teleconference Tanggal 16 Maret 2021

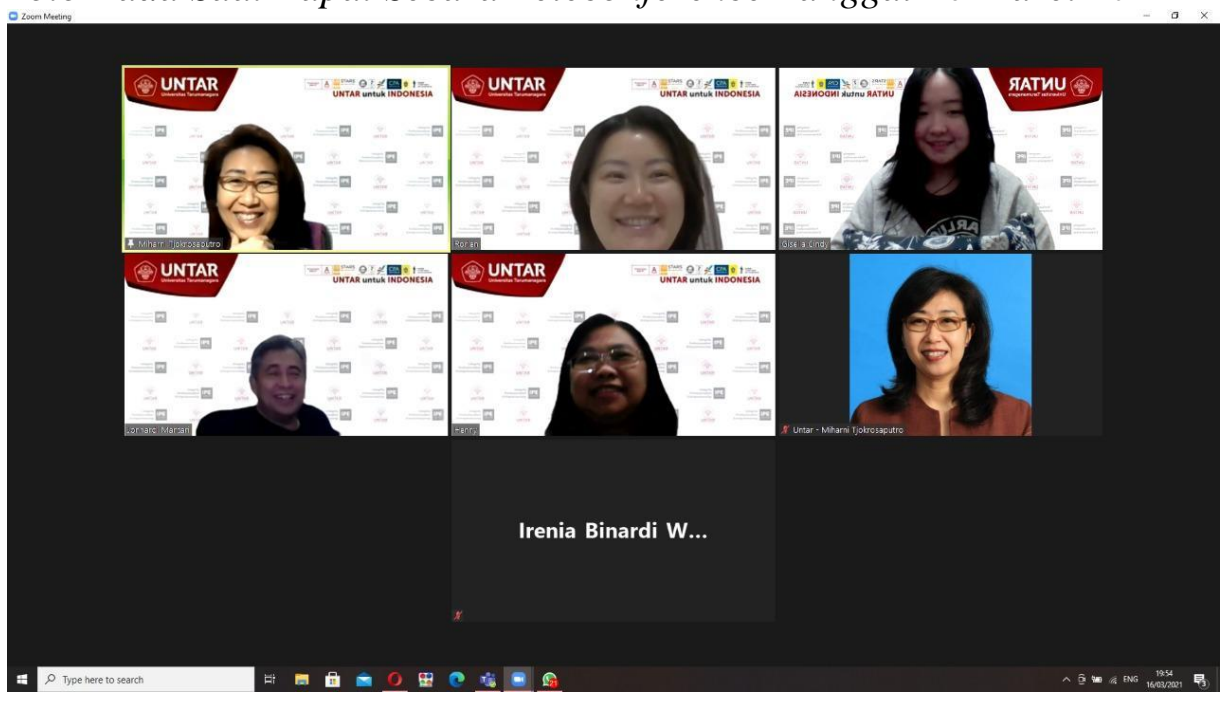

\section{Gambar 3}

\section{Foto pada Saat Kegiatan PKM Tanggal 17 Maret 2021}

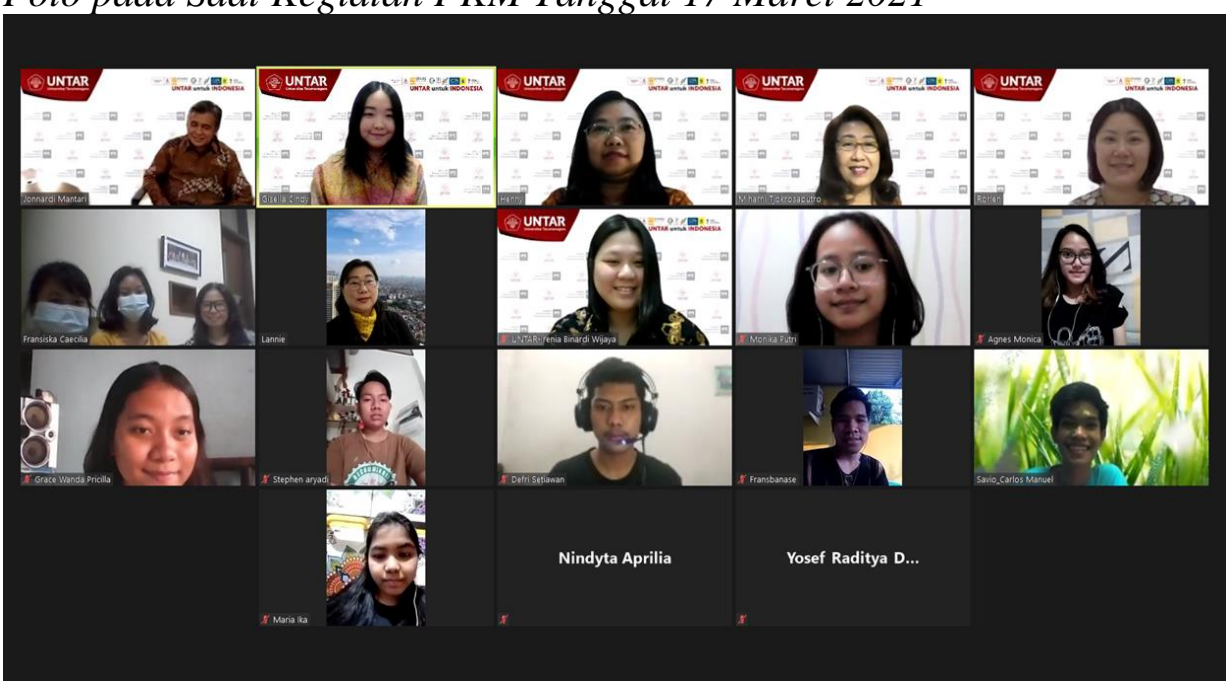




\section{HASIL DAN PEMBAHASAN}

Kegiatan PKM telah dilaksanakan pada hari Rabu, tanggal 17 Maret 2020, melalui aplikasi Zoom. Acara pembekalan motivasi diikuti oleh 14 orang siswa SMA dan 2 mahasiswa binaan ASAK Sathora.

Pemberian materi PKM kepada mitra PKM telah dilakukan 1 hari sebelum kegiatan dilangsungkan. Adapun acara berlangsung pada tanggal 17 Maret 2021 pada pukul $17.00-18.30$ melalui Zoom. Dari 14 peserta yang mendaftar, semuanya hadir. Selain itu, ada 2 orang pengurus ASAK Santo Thomas Rasul yang ikut ambil bagian dalam acara tersebut.

Pada saat pembukaan, ibu Lanny selaku ketua ASAK Sathora untuk anak SMA menyampaikan beberapa kendala yang terjadi karena masa pandemi ini, diantaranya adalah:

1) Peserta pembekalan ini hanya 14 anak karena banyak peserta yang mengundurkan diri terkait pandemi Covid-19 ini.

2) Ada himbauan dari ASAK KAJ agar anak ASAK yang akan mengajukan perkuliahan pada tahun ini sebaiknya mengambil kelas online.

Acara berjalan lancar, dan anak-anak menanggapi dengan antusias dengan beberapa pertanyaan. Adapun beberapa pertanyaan tersebut seperti:

1) Bagaimana dengan kondisi pembelajaran sekarang selama pandemic dengan system luring?

2) Apakah tidak ada program beasiswa untuk anak-anak binaan ASAK?

Dikarenakan anak-anak binaan ASAK mayoritas adalah mereka yang keterbatasan dana untuk melanjutkan kuliah, maka anak-anak sangat mengharapkan adanya program beasiswa yang bisa membantu mereka untuk melanjutkan pendidikan ke jenjang perkuliahan. Hal ini juga disampaikan oleh Ibu Lanny selaku ketua ASAK Santhora.

Evaluasi atas hasil PKM dilakukan melalui kuesioner yang dibagikan kepada peserta PKM melalui google form atas materi yang diberikan. Adapun hasil evaluasi kegiatan PKM yang dilakukan dapat dilihat pada Tabel 3 .

\section{Tabel 3}

Hasil Pengukuran Kegiatan PKM Pemberian Motivasi Kuliah Anak ASAK

\begin{tabular}{|c|c|c|c|}
\hline & Pertanyaan & Jawaban terbanyak & Prosentase \\
\hline 1 & Asal Sekolah: & SMA Swasta & $76,2 \%$ \\
\hline 2 & Kelas & 12 & $95,2 \%$ \\
\hline 3 & Sudah menerima bantuan dana dari ASAK selama: & $>3$ tahun & $100 \%$ \\
\hline 4 & Penyampaian materi: & Sangat baik & $90,5 \%$ \\
\hline 5 & Materi Seminar: & Sangat berguna & $95,2 \%$ \\
\hline 6 & Menurut anda, apakah pola pikir / mindset perlu dibangun? & Sangat perlu & $100 \%$ \\
\hline 7 & $\begin{array}{l}\text { Apakah pola pikir berkembang / growth mindset bisa anda } \\
\text { terapkan dalam kehidupan sehari2? }\end{array}$ & Sangat bisa & $66,7 \%$ \\
\hline 8 & $\begin{array}{l}\text { Apakah materi online seminar ini memotivasi anda untuk } \\
\text { mendorong anda untuk mengembangkan diri? }\end{array}$ & Sangat memotivasi & $71,4 \%$ \\
\hline 9 & Mana yang lebih baik, Pola pikir berkembang atau Fixed mindset & $\begin{array}{l}\text { Pola pikir } \\
\text { berkembang }\end{array}$ & $100 \%$ \\
\hline 10 & $\begin{array}{l}\text { Jika diadakan acara yang lain oleh tim Untar, Apakah anda } \\
\text { tertarik untuk ikut ambil bagian pada acara tersebut? }\end{array}$ & $\mathrm{Ya}$ & $90,5 \%$ \\
\hline
\end{tabular}




\section{KESIMPULAN DAN SARAN}

Masukan dan saran yang dapat diberikan sebagai bahan perbaikan, antara lain:

1) Pemberian motivasi bagi anak ASAK penting dilakukan untuk anak ASAK karena daya juang sebagian anak ASAK relatif rendah.

2) Pelaksanaan kegiatan PKM sebaiknya dilaksanakan di awal semester, sehingga para siswa memiliki waktu lebih banyak.

3) Kegiatan terlalu singkat, dan secara online membuat para siswa tidak bisa sepenuhnya berkonsentrasi pada acara ini karena satu dan lain hal.

4) Diadakan pelatihan tentang pemilihan jurusan di universitas dan tips sukses dalam study dan karir.

5) Universitas Tarumanagara memberikan beasiswa khusus bagi anak binaan ASAK, mengingat ada beberapa anak ASAK yang tertarik untuk studi di Universitas Tarumanagara tetapi terkendala biaya.

\section{Ucapan Terima Kasih (Acknowledgement)}

Tim pelaksana PKM mengucapkan terima kasih kepada Lembaga Penelitian dan Pengabdian kepada Masyarakat (LPPM) Universitas Tarumanagara yang telah memberikan kontribusi dana kegiatan Pengabdian Kepada Masyarakat dan para pengurus ASAK serta siswa SMA binaan ASAK Sathora yang terlibat dalam kegiatan Pengabdian Kepada Masyarakat sehingga kegiatan ini dapat berjalan dengan lancar.

\section{REFERENSI}

Claro, S., Paunesku, D., \& Dweck, C. S. (2016). Growth mindset tempers the effects of poverty on academic achievement. Proceedings of the National Academy of Sciences: Vol. 113. (pp.8664-8668). https://doi.org/10.1073/pnas.1608207113

Crawford, C., Gregg, P., Macmillan, L., Vignoles, A., \& Wyness, G. (2016). Higher education, career opportunities, and intergenerational inequality. Oxford Review of Economic Policy, 32(4), 553-575. https://doi.org/10.1093/oxrep/grw030

Gregg, P., Macmillan, L., \& Vittori, C. (2015). Nonlinear estimation of lifetime intergenerational economic mobility and the role of education (No.15-03). Department of Quantitative Social Science Working Paper University College London. https://repec.ucl.ac.uk/REPEc/pdf/qsswp1503.pdf

Lazowski, R. A., \& Hulleman, C. S. (2016). Motivation interventions in education: A meta analytic review. Review of Educational Research, 86(2), 602-640. https://doi.org/10.3102/0034654315617832

Munro, L. (2011). "Go boldly, dream large!”: The challenges confronting non-traditional students at university. Australian Journal of Education, 55(2), 115-131. https://doi.org/10.1177/000494411105500203

Rhew, E., Piro, J. S., Goolkasian, P., \& Cosentino, P. (2018). The effects of a growth mindset on self-efficacy and motivation. Cogent Education, 5(1), 1-16. https://doi.org/10.1080/2331186X.2018.1492337

Sadeghzadeh, A., Nassiriyar, M., Haghshenas, M., \& Shahbazi, R. (2015). Higher education job satisfaction and relevance to workforce. AASCIT Journal of Education, 1(2), 26-30.

Saenz, V. \& Barrera, D. (2007). What we can learn from UCLA's "First in My Family" data?. Retention in Higher Education, 21(9), 1-3.

Schmidt, H. (2014). Motivations for going to university: A qualitative study and class project. Collected Essays on Learning and Teaching, 7(2), 106-111. https://eric.ed.gov/?id=EJ1060229 
Yeager, D. S., Hanselman, P., Walton, G. M., Murray, J. S., Crosnoe, R., Muller, C., ... \& Dweck, C. S. (2019). A national experiment reveals where a growth mindset improves achievement. Nature, 573(7774), 364-369. https://doi.org/10.1038/s41586-019-1466-y 